\title{
Influence of the processing conditions on the characteristics of the clad layers produced with laminar plasma technology
}

\author{
Wei Ma* \\ Institute of Mechanics, Chinese Academy of Sciences, 15 Beisihuanxi Road, 100080, China \\ Received 5 July 2005; received in revised form 9 November 2005; accepted 9 November 2005 \\ Available online 10 January 2006
}

\begin{abstract}
Laminar plasma technology was used to produce ceramic hardened layers of $\mathrm{Al}_{2} \mathrm{O}_{3}-40 \%$ mass Ni composite powders on stainless steel substrates. In order to investigate the influences of processing conditions on the morphologies of the surface modified layers, two different powderfeeding methods were tested, one with carrier gas called the powder injection method, and the other without carrier gas called powder transfers method. The microscopic investigations demonstrate that the cross-section of the clad layers consists of two distinct microstructural regions, in which the $\mathrm{Al}_{2} \mathrm{O}_{3}$ phases exhibit different growth mechanisms. When the powder transfers method is adopted, the number density and volume fraction of the $\mathrm{Al}_{2} \mathrm{O}_{3}$ particles increase considerably and their distributions exhibit zonal periodical characteristics. When the powder-feeding rate increases, the microstructure of the $\mathrm{Al}_{2} \mathrm{O}_{3}$ phases changes from a small globular to a long needle shape. Finite element simulations show that the transient thermo-physical features of the pool substances, such as solidification rate and cooling rate, influence strongly the mechanisms of the nucleation and the directional growth of the $\mathrm{Al}_{2} \mathrm{O}_{3}$ phases in the thermal processing.
\end{abstract}

(C) 2005 Elsevier B.V. All rights reserved.

Keywords: Laminar plasma technology; Ceramic hardened phase; Powder transfers method; Surface modified layers; Transient thermo-physical features

\section{Introduction}

Surface modifications and coating technologies based on the interaction between plasma streams and solid surfaces have been hot spot for a long time, and are currently widely employed in engineering applications [1-5]. Generally, turbulent plasma streams are chosen as the thermal source to heat the solid surface. Previous studies [6] demonstrate that the convolution effect of the turbulent stream with atmospheric environment is helpful to the entrainment of the input powders when the method of powder injection is adopted, in spite of that the effect will lead to extensive entrainment of external impurities into the plasma stream, degrading greatly the properties of the surface modified layers. However, it is quite different if laminar plasma streams are selected as the thermal source. Since there is no convolution effect, the entrainment of

\footnotetext{
* Tel.: +86 10 82622614; fax: +861062561284

E-mail address: watwm@imech.ac.cn.
}

impurity and atmosphere can be avoided to a great extent, resulting in improved microstructure and alleviated oxidation. However, well-ordered flow field structure and smaller plasma cores often make the penetration of the input powders into the plasma gas steam extremely difficult. In this case, a great number of powder particles move out of the carrying plasma streams and cannot absorb sufficient thermal energy to become molten before deposited on the pool surface, resulting in poor clad layers and low volume fraction of the $\mathrm{Al}_{2} \mathrm{O}_{3}$ phases. Moreover, the laminar plasma technology put forward rigorous requirements on the quality of the input powder [7]. For example, it is necessary that the powders should have quite uniform particle sizes as in the region of $25-45 \mu \mathrm{m}$ so that the disorder movement of the powders can be avoided and the powder particles can be conveniently delivered into the plasma core and sufficiently molten by the slender plasma steams. Therefore, it is necessary to develop an effective powderfeeding technique to work with the laminar plasma technology so that popular commercial powder materials can be expediently employed in the laminar plasma spraying and 
surface modification processing. In fact, the powder-feeding problem has become one of the crucial technical problems, which determines whether the processing can be successfully applied to the field of surface modifications.

Consequently, a renewable powder transfers method is tested in the present studies. It was found that the method could expediently deliver popular commercial powders into the plasma cores. Since the influence of carrier gas is eliminated, the plasma stream can remain in a steady state of layered flow and consequently maintain a high-power output at high thermal efficiency even at a greatly increased powder-feeding rate. The microscopic observations by the scanning electron microscope (SEM) indicate that the powder-feeding method can considerably raise the volume fraction of the $\mathrm{Al}_{2} \mathrm{O}_{3}$ phases in the clad layers and the morphology of the $\mathrm{Al}_{2} \mathrm{O}_{3}$ phases is very sensitive to the powder-feeding rate. For example, the globular $\mathrm{Al}_{2} \mathrm{O}_{3}$ phase develops conspicuously at low feeding rate, whereas the needle-shaped $\mathrm{Al}_{2} \mathrm{O}_{3}$ phase is extensively observed at high feeding rate. The energy dispersive spectroscope (EDS) analysis indicates that the laminar plasma technology along with the powder transfers method hardly induce any oxidation effects on the original $\mathrm{Al}_{2} \mathrm{O}_{3}$ ceramic powders even though they were completely exposed to the extremely high temperature environment and underwent state changes from solid to liquid. In order to investigate the influences of the transient thermo-physical properties on the mechanisms of $\mathrm{Al}_{2} \mathrm{O}_{3}$ phase growth, twodimensional finite element simulations on the solidification process are conducted and relevant discussions are presented.

\section{Experimental details}

A commercial $1 \mathrm{Cr} 18 \mathrm{Ni}$ Ti stainless steel plate with dimensions of $80 \mathrm{~mm} \times 20 \mathrm{~mm} \times 3 \mathrm{~mm}$ is selected as the substrate, which has the following chemical composition (wt.\%): $\mathrm{C} \leq 0.12, \mathrm{Mn} \leq 2.0, \mathrm{Si} \leq 0.80, \mathrm{Cr} 17.07-19.00, \mathrm{Ni}$ 8.00-11.00, $\mathrm{S} \leq 0.025, \mathrm{P} \leq 0.035$, Ti $0.58-0.8$ and balance being Fe. Before treatment, the substrate surfaces were rubbed with 100-300 $\mu \mathrm{m}$ sand paper to enhance its surface roughness. $\mathrm{Al}_{2} \mathrm{O}_{3}-40 \%$ mass $\mathrm{Ni}$ ceramic-metal composite powders with particle size $25-75 \mu \mathrm{m}$ are chosen as the added powders to produce the ceramic hardened layers. Details of the processing condition related to the laminar plasma clad treatment can be found in Refs. [7,8].

In order to investigate the influences of powder-feeding method on the microstructures of the surface modified layers, two different methods are tested: one is the common method of powder injection with carrier gas and the other is the renewable powder transfers method without carrier gas. In the former case (Fig. 1), the carrier gas of argon is used to inject the $\mathrm{Al}_{2} \mathrm{O}_{3}$ powder into the laminar plasma cores. The flow rate is about $5 \mathrm{~cm}^{3} / \mathrm{s}$ and the powder-feeding rates is $3-5 \mathrm{~g} / \mathrm{min}$. In the latter case (Fig. 2), a stainless steel tube, working as the transfer's vehicle to replace the carrier gas, is used to deliver the added powder. Before testing, the steel tube, which has the identical composition as the substrate and the dimensions of $\Phi$ $2 \mathrm{~mm} \times 0.1 \mathrm{~mm}$, was filled with the $\mathrm{Al}_{2} \mathrm{O}_{3}$ powder. During cladding, the $\mathrm{Al}_{2} \mathrm{O}_{3}$ powder together with the steel tube was directly plunged into the plasma cores to implement the powder transfer. The moving speed and geometry of the steel tube determine completely the powder-feeding rates. For comparison between the two methods, an identical feeding rate is first selected, and then a high powder-feeding rate of $10-12 \mathrm{~g} / \mathrm{min}$ is tested to determine an appropriate processing condition suited to the powder transfers method.

The metallographic specimens fabricated with the two powder-feeding methods were prepared for microscopic investigations. The SEM was used to examine the microstructures and morphologies of the clad layers. The EDS analysis determined quantitatively the contents of the $\mathrm{Al}$ and $\mathrm{O}$ elements and investigated the oxidation effects of the $\mathrm{Al}_{2} \mathrm{O}_{3}$ particles occurring in the cladding processing. X-ray diffraction (XRD) spectrum method was used to analyze the phase
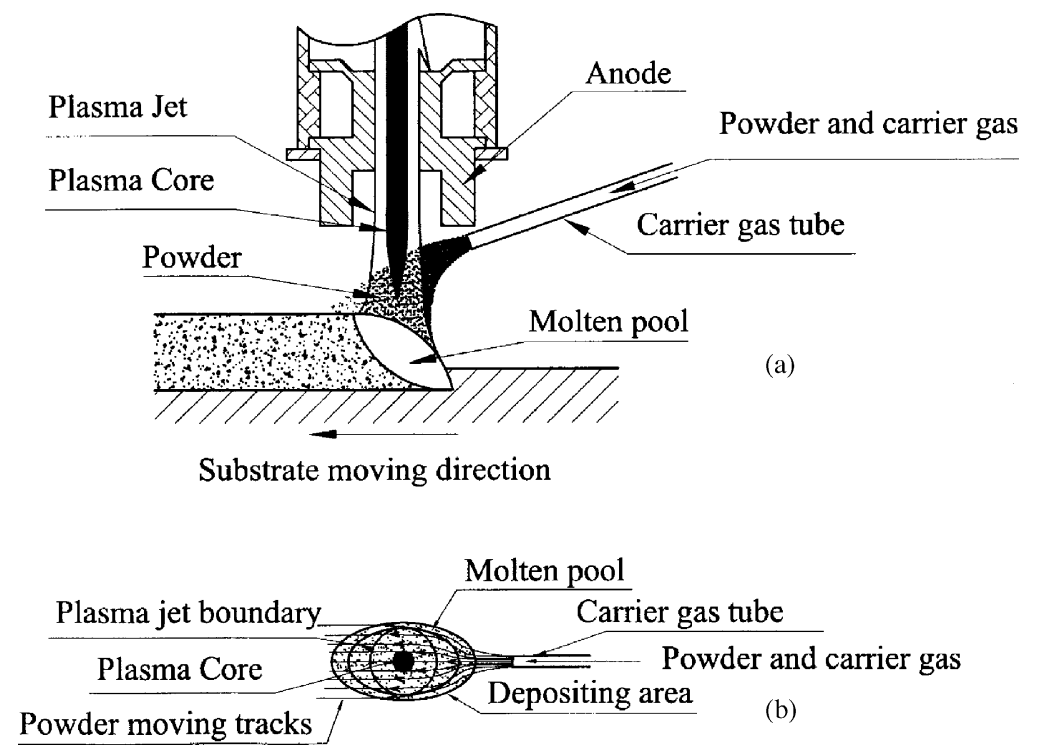

Fig. 1. (a) Schematic diagram of the powder injection method and (b) the deposition status on the substrate. 


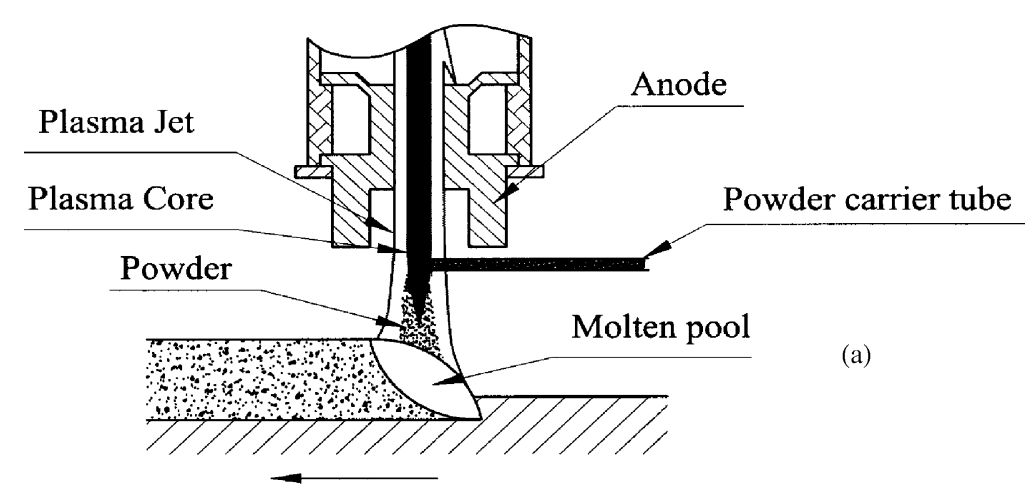

Substrate moving direction

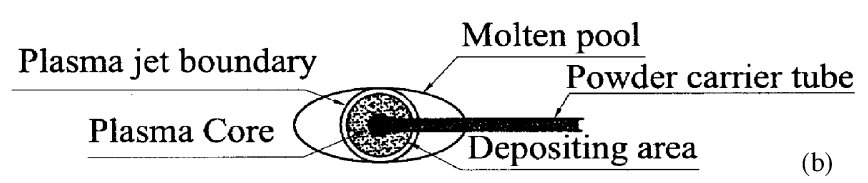

Fig. 2. (a) Schematic diagram of the powder transfers method and (b) the deposition status on the substrate.

constituents of the $\mathrm{Al}_{2} \mathrm{O}_{3}$. The measurement of the Vickers hardness along the depth direction of the clad layers was conducted on the MH-6 semi-automatic Vickers hardness tester with a load of $2 \mathrm{~N}$ and an acting time of $10 \mathrm{~s}$.

\section{Experimental results}

The microstructure of the $\mathrm{Al}_{2} \mathrm{O}_{3}$ hardened layer produced with the powder injection method is illustrated in Fig. 3a. It can be seen that only the discrete $\mathrm{Al}_{2} \mathrm{O}_{3}$ particles are segregated and uniformly distributed in the clad layer. Some $\mathrm{Al}_{2} \mathrm{O}_{3}$ particles precipitate in the interdendritic areas and the remainders grow in the interior of the grains. The volume fraction of the $\mathrm{Al}_{2} \mathrm{O}_{3}$ phases was, in a statistical sense, estimated to be approximately $2 \%$ by comparing the difference of contrast of the particles on the cross-section. More detailed observation on the microstructure is illustrated in Fig. 3b, which shows that some microcracks and cavities have developed in the clad processing.
Perhaps the disturbance of the carrier gas to the laminar plasma streams, which usually results in the existence of non-molten and partially molten $\mathrm{Al}_{2} \mathrm{O}_{3}$ particles, is the main cause of these defects.

Fig. 4a illustrates that the metallographic structure in the transverse plane of a sample prepared by the powder transfers method at the feeding rate of 3-5 g/min. Dendrite characteristic of a typical rapid growth in the solidification process can be seen. The zonal periodical distribution characteristic of $\mathrm{Al}_{2} \mathrm{O}_{3}$ phase clearly demonstrates the mechanism of grain directional growth during solidification. For showing the microstructure and the distribution of the $\mathrm{Al}_{2} \mathrm{O}_{3}$ phases in more detail, a highmagnification micrograph of the cross-section is illustrated in Fig. $4 \mathrm{~b}$. Inside the grain, the $\mathrm{Al}_{2} \mathrm{O}_{3}$ particles are very fine and their microstructural scales are just in the order of sub-micron. In the region where the microstructure was characterized by randomly growing mechanisms, discrete $\mathrm{Al}_{2} \mathrm{O}_{3}$ particles were incorporated in these grains and were uniformly distributed
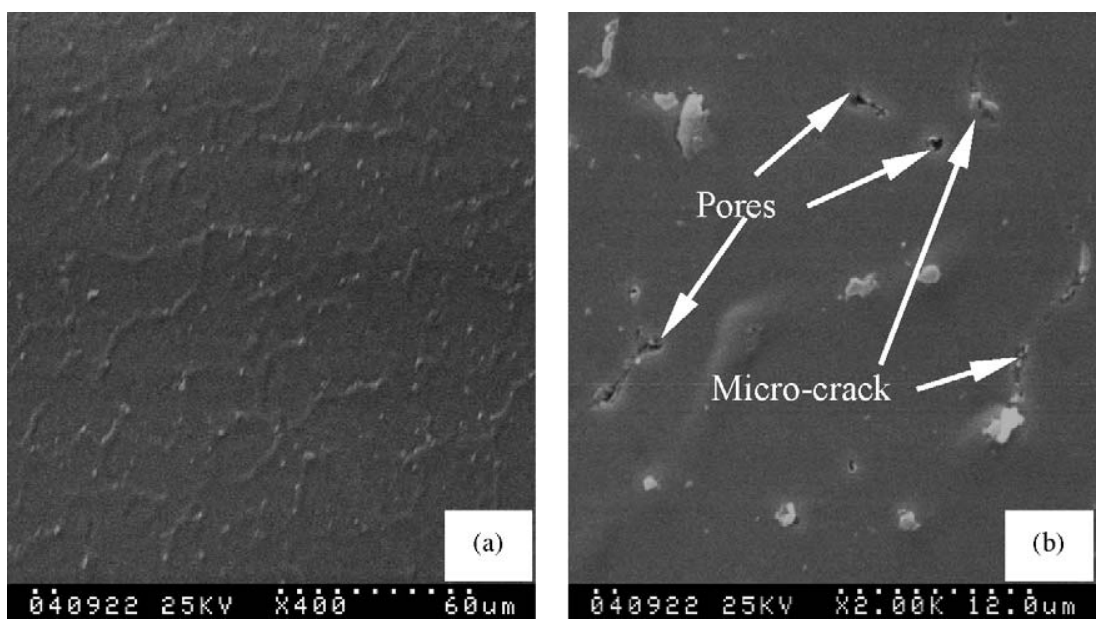

Fig. 3. (a) The microstructure of the clad layer prepared by the powder injection method and (b) detailed observation of the cross-section microstructure. 

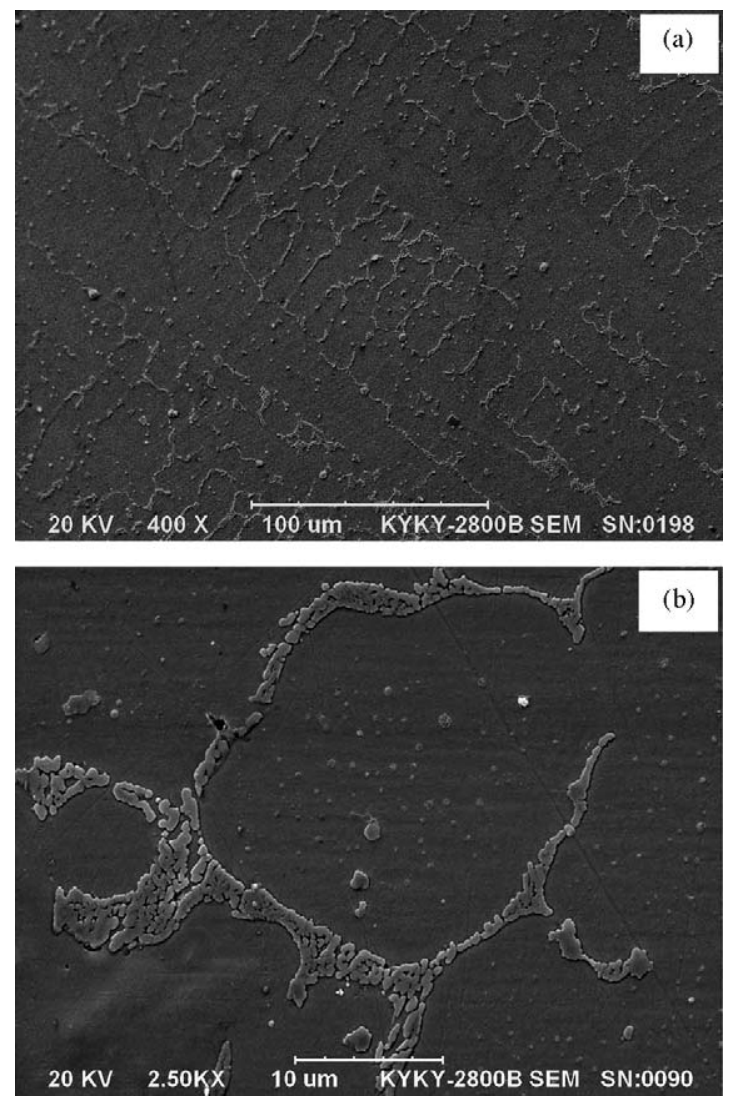

Fig. 4. (a) The microstructure of the clad layer prepared by the powder transfers method and (b) the $\mathrm{Al}_{2} \mathrm{O}_{3}$ phases precipitate inside the grain and in the interdendritic areas.

within. However, most of the $\mathrm{Al}_{2} \mathrm{O}_{3}$ particles were rejected from the grains and segregated in the interdendritic areas. In the regions the microstructure of the $\mathrm{Al}_{2} \mathrm{O}_{3}$ phases was mainly characterized by eutectic phases, the difference of which was only their thickness, and therefore the $\mathrm{Al}_{2} \mathrm{O}_{3}$ phases appeared in either line-shaped or bulk distribution. These results reveal that the $\mathrm{Al}_{2} \mathrm{O}_{3}$ particles have ever gone through a re-solidified process from completely molten to rapid solidification. The statistical results indicate that the volume fraction of the $\mathrm{Al}_{2} \mathrm{O}_{3}$ phases reaches $8.5 \%$ or so.

A comparison of the microstructures of the sample prepared by the powder transfers method, but at a different powderfeeding rate of $10-12 \mathrm{~g} / \mathrm{min}$, clearly indicates that the powderfeeding rate has significant effects on the microstructure of the clad layer, as well as on the morphology, volume fraction and growth mechanism of the $\mathrm{Al}_{2} \mathrm{O}_{3}$ phases in the modified layer (Fig. 5a). At high powder-feeding rate, the basic morphology of the $\mathrm{Al}_{2} \mathrm{O}_{3}$ phase changes from the globular structure (Fig. 4) to the needle-shaped structure that has a mean diameter of $500 \mathrm{~nm}$ and a typical length between 5 and $10 \mu \mathrm{m}$. The higher the powder-feeding rate, the larger the size of the $\mathrm{Al}_{2} \mathrm{O}_{3}$ phases and the higher the volume fraction of the $\mathrm{Al}_{2} \mathrm{O}_{3}$ phases in the clad layer. In different regions of the cross-section, the evolution of the needle-shaped $\mathrm{Al}_{2} \mathrm{O}_{3}$ phases is characterized by quite different directional growth mechanisms. In the upper region, the growth direction is perpendicular to the view plane so that
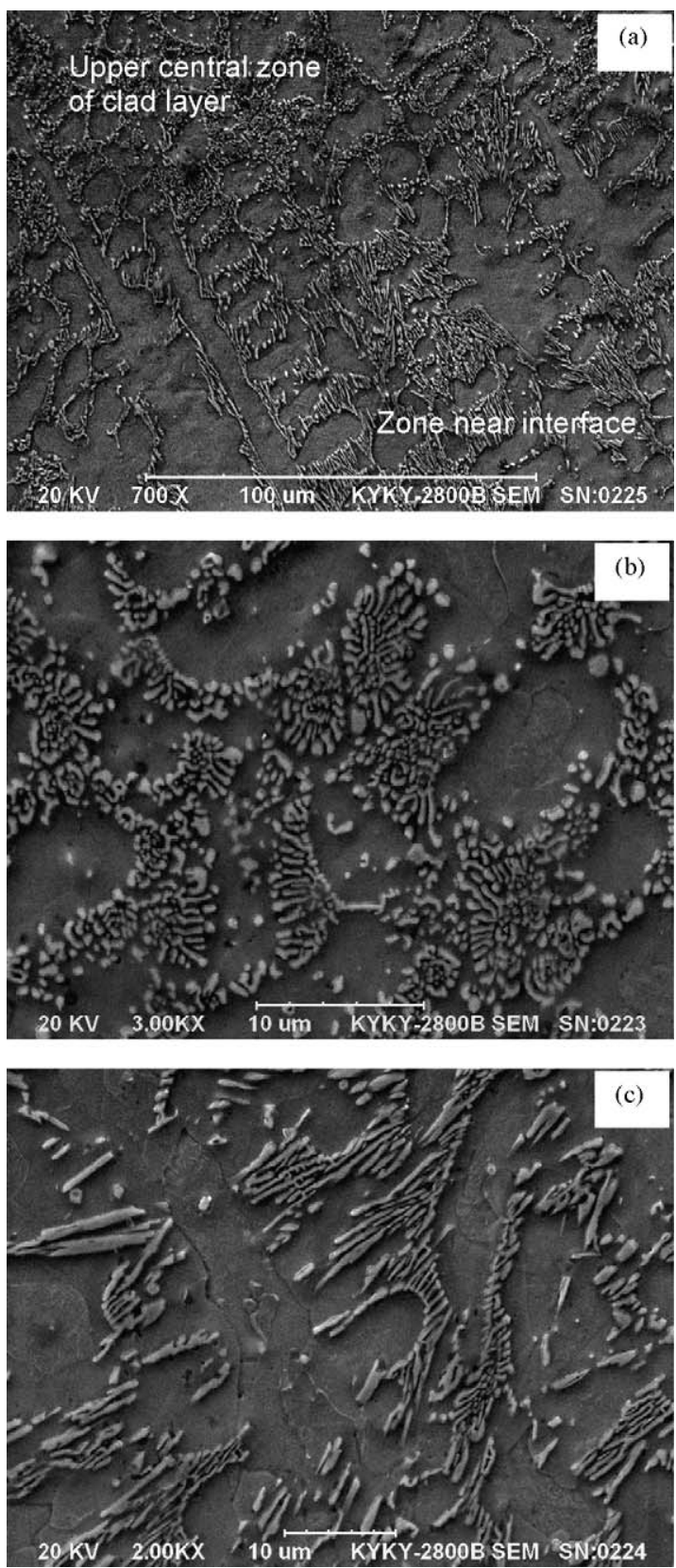

Fig. 5. (a) The microstructure of the clad layers prepared by the powder transfers method at the feeding rate of $10-12 \mathrm{~g} / \mathrm{min}$. The needle-shaped $\mathrm{Al}_{2} \mathrm{O}_{3}$ phases appear in the top region (b) and the bottom region (c) of the clad layer.

the transverse profiles of the $\mathrm{Al}_{2} \mathrm{O}_{3}$ phases can be seen clearly (Fig. 5b). In the region near the interface between the clad layer and the substrate, the growth direction is situated within the cross-section; hence, the typical needle-shaped structure can be seen (Fig. 5c). It is similar to the case of low powder-feeding rate that the microstructure of the clad layer still revealed the zonal periodical distribution feature of the $\mathrm{Al}_{2} \mathrm{O}_{3}$ phases, and the $\mathrm{Al}_{2} \mathrm{O}_{3}$ particles are segregated likewise in the interdendritic areas. Moreover, from the region near the interface to the upper region of the clad layer, the volume fraction of the $\mathrm{Al}_{2} \mathrm{O}_{3}$ phases increases gradually and the maximum volume fraction reaches 


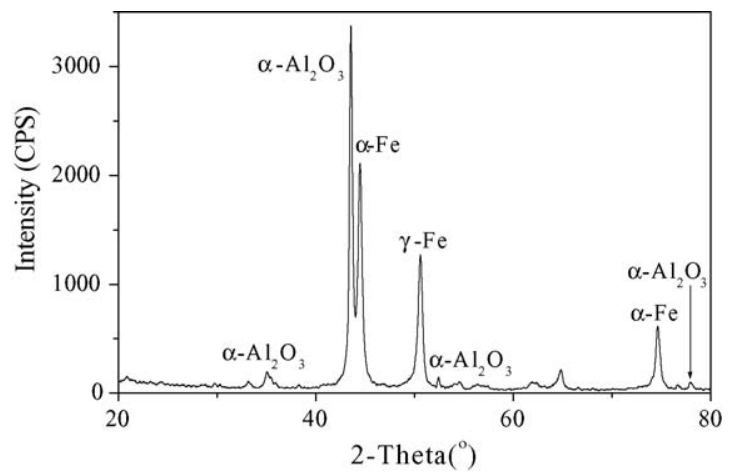

Fig. 6. X-ray diffraction pattern of the $\mathrm{Al}_{2} \mathrm{O}_{3}$ clad layer prepared by the powder transfers method.

$37 \%$ or so. The XRD spectrum analysis of the clad layer (Fig. 6) shows that the phase constituents consist principally of $\alpha$ $\mathrm{Al}_{2} \mathrm{O}_{3}, \alpha-\mathrm{Fe}$ and $\gamma$-Fe. However, in the case of low powderfeeding rate, it was difficult to identify the phase constituents of the $\mathrm{Al}_{2} \mathrm{O}_{3}$ phases because the volume fraction is too small to be detected by the XRD instrument.

Fig. 7a illustrates the EDS compositional analysis spectrum of the cross-section of the sample shown in Fig. 5a. The element concentrations of the $\mathrm{Al}_{2} \mathrm{O}_{3}$ phases are (wt.\%): $\mathrm{Al}, 49.17$; $\mathrm{O}$, $42.02 ; \mathrm{Ni}, 7.39 ; \mathrm{Fe}, 1.42$. This result suggests that the clad layer consists mainly of $\mathrm{Al}$ and $\mathrm{O}$. The elements $\mathrm{Ni}$ and $\mathrm{Fe}$ existing in small quantity come from the original $\mathrm{Al}_{2} \mathrm{O}_{3}-40 \%$ mass $\mathrm{Ni}$ composite powder and the steel tube, respectively. The EDS analysis result of the original input $\mathrm{Al}_{2} \mathrm{O}_{3}$ powders is illustrated
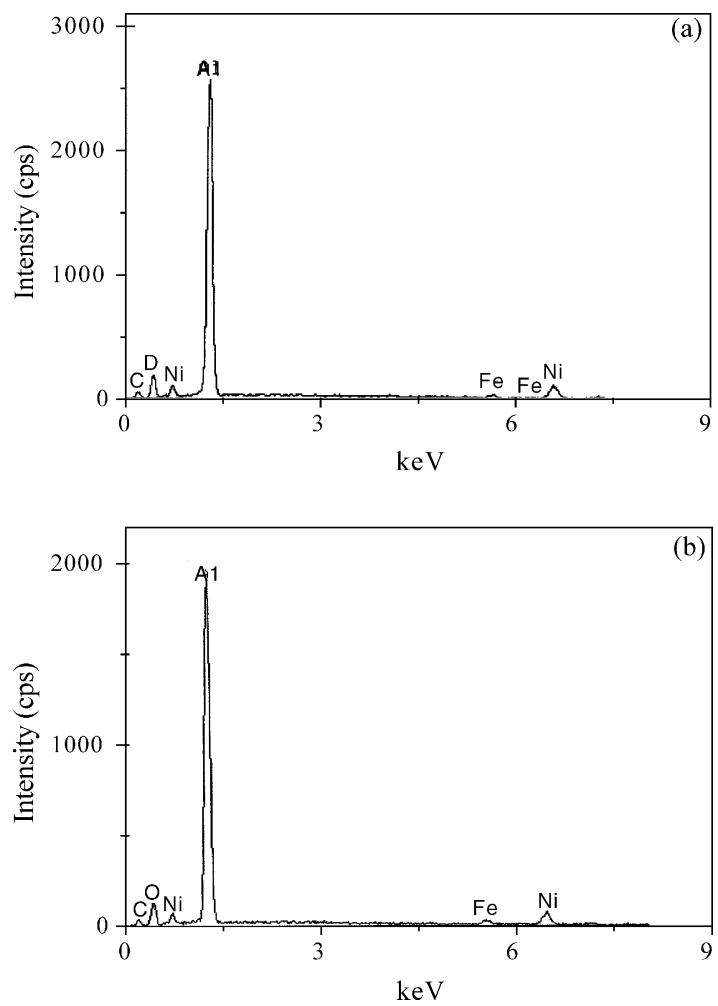

Fig. 7. The EDS analysis result of the $\mathrm{Al}_{2} \mathrm{O}_{3}$ phases in the clad layer (a) and the original powder (b).

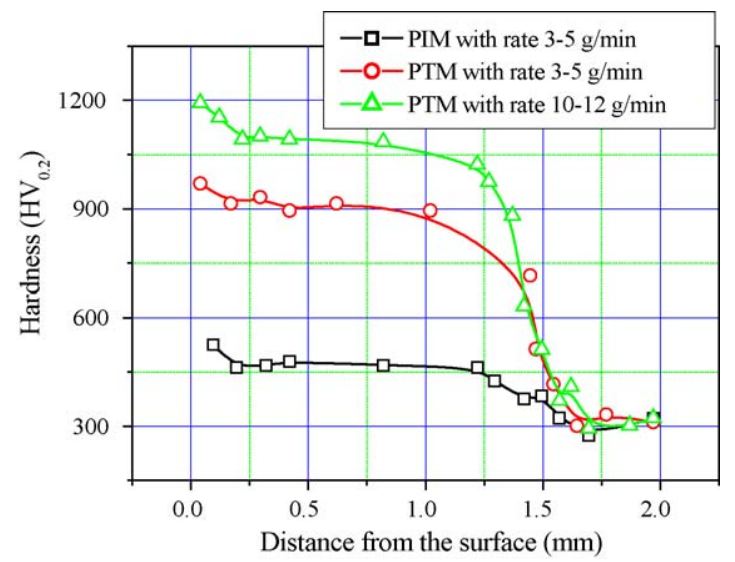

Fig. 8. Distribution of the hardening of the $\mathrm{Al}_{2} \mathrm{O}_{3}$ clad layers.

in Fig. 7b. The element concentrations are (wt.\%): Al, 50.44; O, $41.56 ; \mathrm{Ni}, 6.39 ; \mathrm{Fe}, 1.61$. It is noticed that only minor variations of concentrations of the main elements $\mathrm{Al}$ and $\mathrm{O}$ are detected, although the $\mathrm{Al}_{2} \mathrm{O}_{3}$ powders experienced the state change from solid to liquid. This fact implies that the adoption of the powder transfers technique in the laminar plasma processing can effectively prevent the oxidation of the input $\mathrm{Al}_{2} \mathrm{O}_{3}$ powders.

The Vickers hardness profiles of the three typical clad layers discussed above are illustrated in Fig. 8. The different volume fractions of the $\mathrm{Al}_{2} \mathrm{O}_{3}$ phases as well as the dissimilar microstructures of the clad layers exhibit quite different hardness characteristics. The averages of the clad layers prepared by the powder transfers method reach about $\mathrm{HV}_{0.2} 910$ and $\mathrm{HV}_{0.2} 1060$, respectively; while that with the powder injection method is only about $\mathrm{HV}_{0.2} 420$. Each datum shown in the figure is an average of four measurements taken at the same depth from the surface of the clad layers. It is noticeable that, for the clad layer prepared by the powder transfers method and at the powder-feeding rate of 3-5 g/min, a gradual change in the hardness is demonstrated from the clad layer to the substrate, which suggests a flat transition in materials properties across the whole interface.

\section{Numerical simulation and discussion}

The properties of the surface modified layers are closely related to the transient features of substance solidification. The clad treatment is an extremely complicated process, involving grain growth, phase transformation, heat and mass transfer, substance gasification and state change. Therefore, in order to formulate an analytic model to carry out finite element simulations, some specific simplifications about the clad process must be made. At present, relevant simplified assumptions include: (i) if major attention is focused on the transient solidification, the heat exchange with the surrounding medium is of minor importance. Thus, the transient thermophysical problem describing the clad process is assumed to satisfy adiabatic boundary conditions, which apply to the top and bottom surfaces of the sample; (ii) because the temperature gradient in the cross-section is much more larger than that in the longitudinal section [9], the heat flow is limited mainly in 


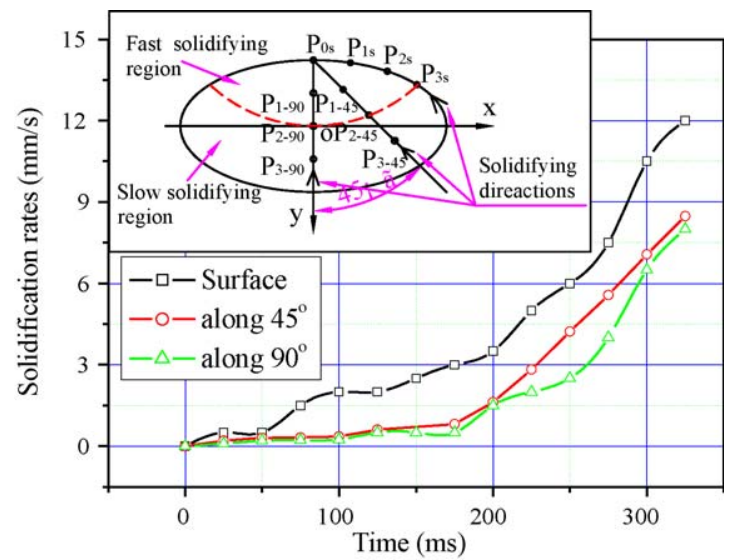

Fig. 9. The solidification rates along the surface border, and along $45^{\circ}$ and $90^{\circ}$ radials.

the transverse cross-section; (iii) it is hard to picture the difference of the transient temperature fields on two arbitrary transverse cross-sections of the track except for a limited delay in time. This fact implies that the transient thermal properties of the pool substance are essentially invariable along the track longitudinal direction and dependent only on the variables in the cross-section; (iv) since the velocity convection in the pool liquid is much weaker than that of the heat conduction [10], the effect of pool substance convection is neglected, and only the effect of heat conduction is considered; (v) the increase of the clad layer in thickness is at a constant growth rate and its specific value is experimentally determined to be about $0.6 \mathrm{~mm} / \mathrm{s}$. Under these hypotheses, a two-dimensional finite element model is established to carry out numerical simulations of the transient heat conduction problem. Details of the mathematical model and the corresponding governing equations are given in Appendix A.

Studies in [11-13] showed that the crystal growth and the microstructure evolution of the clad layers were closely related to the solidification rate and cooling rate. In the cladding process using stable high-power laminar plasma streams, the microstructure evolution is restricted to follow closely the heat flow, which is perpendicular to the moving solid/liquid interface. Therefore, the growths of the dendrites and the second phase particles usually take place ahead of the solidification fronts. Fig. 9 illustrates the variations of the solidification rates with time along three curves on the transverse cross-section, which are, respectively, the surface border of the molten pool and two lines along the $45^{\circ}$ direction and the vertical direction (see the inset of the figure). The arrows on these curves indicate roughly the moving trends of the solidification fronts. In the initial stage of the solidification $(<0.25 \mathrm{~s})$, a slow solidification process occurs in the area near the interface. The solidification rates are, respectively, less than $3 \mathrm{~mm} / \mathrm{s}$ on the pool surface and less than $1.5 \mathrm{~mm} / \mathrm{s}$ at the pool bottom. The corresponding cooling rates are below $1000{ }^{\circ} \mathrm{C} / \mathrm{s}$ (Fig. 10). Such a thermal process provides an advantage of being able to produce equiaxial growth of large dendrite crystals. Similarly, it is also beneficial to the directional growth of the needle-shaped $\mathrm{Al}_{2} \mathrm{O}_{3}$ phases along their length direction. In addition, the low content of the $\mathrm{Al}_{2} \mathrm{O}_{3}$ particles

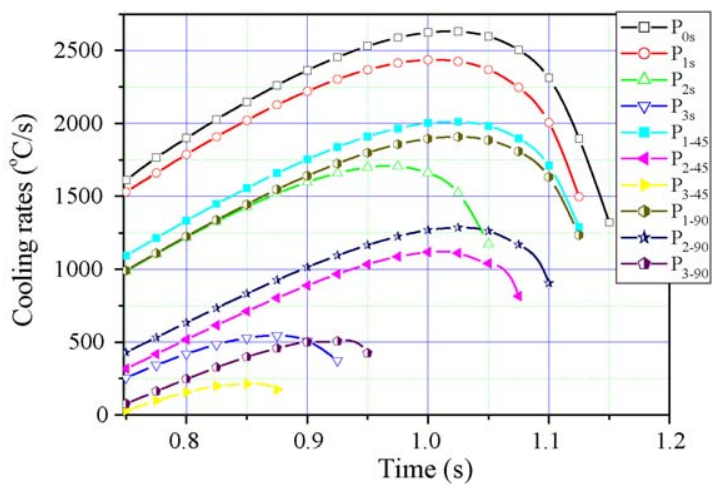

Fig. 10. The relationship of the cooling rates vs. time on 10 specific points.

limits the nucleation density of randomly distributed $\mathrm{Al}_{2} \mathrm{O}_{3}$ phases. Consequently, coarse structures of the dendrites and needle-shaped $\mathrm{Al}_{2} \mathrm{O}_{3}$ phases develop extensively in the area (Fig. 5c).

In later stage of the solidification from 0.25 to $0.32 \mathrm{~s}$, the solidification rates reach $5-12 \mathrm{~mm} / \mathrm{s}$ and the cooling rates are above $1000{ }^{\circ} \mathrm{C} / \mathrm{s}$. In contrast to the slow solidification process, these thermo-physical characteristics imply that the $\mathrm{Al}_{2} \mathrm{O}_{3}$ phases in the upper area of the pool experienced a very fast solidifying course for nucleation and directional growth, which is helpful for fine microstructures of the $\mathrm{Al}_{2} \mathrm{O}_{3}$ phases to evolve [14]. On the one hand, the high content of the $\mathrm{Al}_{2} \mathrm{O}_{3}$ particles enhances the nucleation density of the $\mathrm{Al}_{2} \mathrm{O}_{3}$ phases, and the fast solidifying course reduces considerably the time period for directional growths. Hence, the evolution of the needle-shaped $\mathrm{Al}_{2} \mathrm{O}_{3}$ phases is confined to their fast scale directions, that is, the radial directions of the needle-shaped particles. On the other hand, because of the increase of volume fraction of $\mathrm{Al}_{2} \mathrm{O}_{3}$ phases, the dendrite growth falls into rapid growth of a few grains of a fully re-crystallized microstructure, which is stabilized by $\mathrm{Al}_{2} \mathrm{O}_{3}$ phase particles. Therefore, a great number of transverse structures consisting of $\mathrm{Al}_{2} \mathrm{O}_{3}$ phases are observed in the upper area (Fig. 5b). Furthermore, the $\mathrm{Al}_{2} \mathrm{O}_{3}$ phases precipitate always preferentially in the interdendritic area, which seems to be associated with neither the transient thermal features nor the nucleation density of the $\mathrm{Al}_{2} \mathrm{O}_{3}$ phases.

It can be concluded from the above discussion that there is a critical value for the solidification rate or the cooling rate, at which the orientation of the $\mathrm{Al}_{2} \mathrm{O}_{3}$ phase directional growth changes from the tangent direction to the normal direction of the transverse cross-section of the clad track, while the dendrite growth changes from the equiaxial growth with large scales to that with small scales. From the finite element simulations (Figs. 9 and 10), we can see that the transition points are at the time about $0.25 \mathrm{~s}$ after the initiation of the solidification process. The corresponding solidification rate and cooling rate are respectively about $4.5 \mathrm{~mm} / \mathrm{s}$ and $1260{ }^{\circ} \mathrm{C} / \mathrm{s}$. Hence, the cross-section can be divided into two distinct regions with different microstructure, illustrated by the dashed line as shown in the inset of Fig. 9. In the region above the dashed line corresponding to the fast solidification process, the $\mathrm{Al}_{2} \mathrm{O}_{3}$ phase grows mainly along the normal direction of the track's 
cross-section, whereas in the region below the dashed line corresponding to the slow solidification process, the $\mathrm{Al}_{2} \mathrm{O}_{3}$ phase grows within the cross-section. However, the experimental observation demonstrates that the slow solidification region is principally constricted in the area near the interface between the clad layer and the substrate. Clearly, the discrepancy comes from the simplified model, where the effects of neither heat transfer nor liquid convection were considered.

How to reduce the oxidation of the input powders is a technical problem crucial to the plasma treatments. We have seen that the powder-feeding technique plays an important role in preventing the oxidation occurring in the laminar plasma processing. In the case of the method of powder injection, the influences of carrier gas are quite obvious. For instance, the stable flow state of the laminar plasma streams is, more or less, disturbed by the carrier gas. Usually, the carrier gas carries along the suspended impurity particles in the plasma streams and, simultaneously, makes some powder particles leaving the plasma streams and scattered into atmosphere (Fig. 1). Moreover, the deposition rates and the molten states of the input powder were closely dependent on the powder qualities such as the particle size [7]. Experimental studies demonstrated that full or partial molten large particles usually traversed across the plasma streams, whereas small powder particles or droplets were often rebounded from the outer borders of the plasma streams before deposited on the pool surfaces. Hence, they experienced large temperature fluctuations and exposed temporarily to atmospheric oxygen concentrations, leading to rapid oxidation of the suspended powders in atmospheric environment. However, if the powder transfers method is adopted, the influences of the carrier gas can be totally removed since there is no carrier gas at all. Therefore, the plasma stream can always remain in steady laminar state. When a proper powder-feeding rate is selected, the input powder can be easily delivered into the plasma cores and completely molten. Furthermore, owing to the absence of initial momentum, the $\mathrm{Al}_{2} \mathrm{O}_{3}$ particles can keep dwelling inside the plasma stream and move in the axial direction before deposited on the pool surface (Fig. 2). During the whole process, the plasma working gas plays the role of shielding gas to effectively protect the powder particles from oxidation.

\section{Conclusion}

Main conclusions can be drawn as follows:

(1) By adopting the laminar plasma technology, the $\mathrm{Al}_{2} \mathrm{O}_{3}$ ceramic hardened layers can be obtained that consist of discrete $\mathrm{Al}_{2} \mathrm{O}_{3}$ phases precipitating inside the grains and line-shaped or bulk $\mathrm{Al}_{2} \mathrm{O}_{3}$ phases in the interdendritic areas. The distributions of the $\mathrm{Al}_{2} \mathrm{O}_{3}$ phases on the cross-section of the clad tracks exhibit evident zonal periodical characteristics. From the bottom to the top surface of the clad layer, the volume fractions and the directions of the $\mathrm{Al}_{2} \mathrm{O}_{3}$ phase directional growths change considerably. At low feeding rate, the globular $\mathrm{Al}_{2} \mathrm{O}_{3}$ phase grows extensively. As the feeding rate increases, the needleshaped $\mathrm{Al}_{2} \mathrm{O}_{3}$ phase develops more conspicuously.

(2) The microstructure of the clad layers is closely related to the transient thermo-physical properties of the pool substance. The finite element simulations show that the slow solidification process provides an advantage for the directional growth of the needle-shaped $\mathrm{Al}_{2} \mathrm{O}_{3}$ phases in the cross-section of clad tracks, and the fast solidification rate is of great benefit to the $\mathrm{Al}_{2} \mathrm{O}_{3}$ phase nucleation.

(3) The powder transfers method is successfully applied to the laminar plasma processing, in which not only the input powders can be expediently delivered into the small plasma cores and completely molten, but also the rigorous requirements on their qualities, such as the uniformity of particle sizes, well behaved in flows and so on, are greatly alleviated. Moreover, this method can effectively prevent the input powders from oxidation during the plasma processing.

\section{Acknowledgements}

The National Natural Sciences Foundation of China (no. 10275085) is acknowledged for her financial support to this work.

\section{Appendix A}

For the transient heat conduction occurring in the laminar plasma clad processing, the governing equation of the transient temperature fields is given as follows:

$\nabla\left[k(T) \nabla T_{n}^{(m)}(x, y, t)\right]=\rho c(T) \frac{\partial T_{n}^{(m)}(x, y, t)}{\partial t}$

where $x, y$ are the horizontal and vertical coordinates shown in Fig. A 1 and $t$ is the time, $\nabla=(\partial / \partial x) i+(\partial / \partial y) j$ is the Hamilton operator, and $i, j$ are the unit vectors of the coordinates $x$ and $y$, respectively. $T_{n}^{(m)}(x, y, t) \quad(m=I-I V)$ stand for the temperature distributions of the four stages corresponding to the pre-melting, melting, solidifying and post-solidification, respectively. The subscript $n=l$ and $s$ represent the liquid and solid phases on the cross-section of the modified substrates, respectively. $k(T), \rho$ and $c(T)$ are the heat conductivity, density and specific heat of material related to the current temperatures, respectively. The initial condition is $T^{(\mathrm{I})}(x, y, 0)=T_{0}$, where $T_{0}$ is the surrounding temperature. The governing Eq. (A1) satisfy the boundary conditions in the four phases as following:

$$
\begin{aligned}
\kappa(T) & \frac{\partial T_{\mathrm{s}}^{(m)}(x, y, t)}{\partial x_{1}} \\
\quad= & \begin{cases}Q(x, t) & |x|<2 a(t), \quad y=0, \quad x_{1}=y \\
0 & |x|>2 a(t), \quad y=0, h, \quad x_{1}=y \\
0 & y= \pm L, \quad x_{1}=x ; \quad(m=I-I V)\end{cases}
\end{aligned}
$$




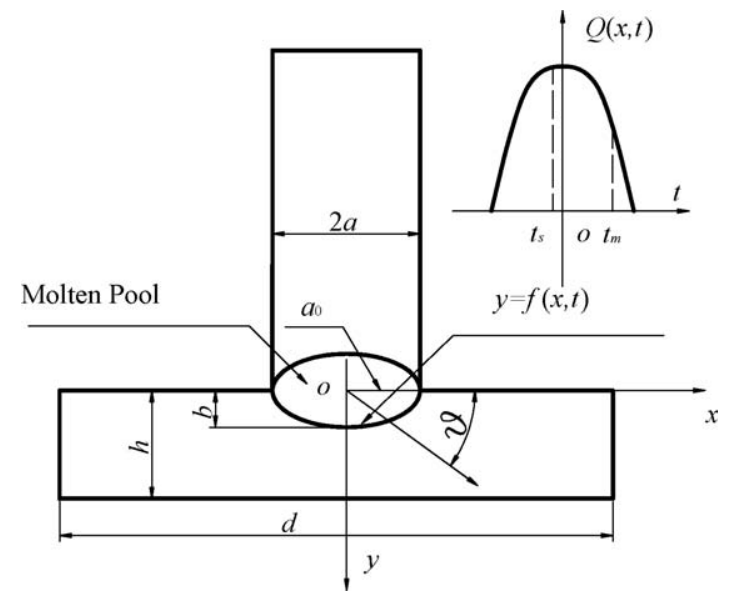

Fig. A1. The two-dimensional finite element model.

where $\kappa(T)$ is the thermal diffusivity and $Q(x, t)$ is the plasma source intensity:

$$
\begin{aligned}
Q(x, t)= & \beta Q_{0}\left[\mathrm{e}^{-\left(x / a_{0}\right)^{2}}-\mathrm{e}^{-\left(a(t) / a_{0}\right)^{2}}\right] \\
& \times\left[\mathrm{e}^{-\left(\left(t / t_{0}\right)-\left(a_{0} / t_{0} V\right)\right)^{2}}-\mathrm{e}^{-\left(a_{0} / t_{0} V\right)^{2}}\right]
\end{aligned}
$$

where $a(t)=\left[a_{0}^{2}-\left(a_{0}-V t\right)^{2}\right]^{1 / 2} . V$ is the moving velocity of the samples and $a_{0}$ the radii of the spot of the plasma jet on the sample surface (Fig. A1). At present, we assume that the plasma source has the Gaussian distribution characteristics related to the spatial coordinate $x$ and the time $t . \beta$ is the absorptivity of material with value $22-30 \%$ [10-12], $Q_{0}$ and $t_{0}$ are the amplitude of the thermal density and the scanning time of the plasma jets with the values of $4 \times 10^{7} \mathrm{~W} / \mathrm{m}^{2}$ and $1.33 \mathrm{~s}$, respectively.
The conditions of energy balance and temperature continuity at the liquid/solid interface are expressed as follows:

$$
\begin{aligned}
& {\left[1+\left(\frac{\partial f}{\partial x}\right)^{2}\right]\left[k_{\mathrm{s}} \frac{\partial T_{\mathrm{s}}^{(m)}}{\partial y}-k_{1} \frac{\partial T_{1}^{(m)}}{\partial y}\right]=\rho_{\mathrm{s}} L \frac{\partial f}{\partial t}} \\
& \left.T_{\mathrm{s}}^{(m)}(x, y, t)\right|_{y=f(x, t)}=\left.T_{1}^{(m)}(x, y, t)\right|_{y=f(x, t)}=T_{m} \\
& \quad(m=I I, I I I)
\end{aligned}
$$

where $L$ is the latent heat of melting/solidification per unit mass of the material, $\rho_{\mathrm{s}}$ is the density of solid phases and $y=f(x, t)$ is the location function of the liquid/solid interface.

\section{References}

[1] A. Lepone, H. Kelly, D. Lamas, A. Marquez, Appl. Surf. Sci. 143 (1999) 124.

[2] J.L. He, K.W. Won, J.T. Chang, Thin Solid Films 359 (2000) 46.

[3] M.N. Vasiliev, A.H. Mahir, Surf. Coat. Technol. 180-181 (2004) 132.

[4] Z.K. Shang, Z.Y. Xu, X.W. Deng, et al. Surf. Coat. Technol. 131 (2000) 109.

[5] Z. Werner, J. Piekoszewski, W. Szymczyk, et al. Surf. Coat. Technol. 158159 (2002) 21.

[6] E. Pfender, Plasma Chem. Plasma Process. 19 (1999) 1.

[7] W. Ma, W.X. Pan, C.K. Wu, Surf. Coat. Technol. 191 (2005) 166.

[8] W. Ma, Q.X. Fei, W.X. Pan, C.K. Wu, in: Proceedings of the 7th Asia Pacific Conference on Plasma Science and Technology and 17th Symposium on Plasma Science for Materials, Fukuoka city, Japan, June 29thJuly 2nd, (2004) p. 29.

[9] S.A. David, J.M. Vitek, Int. Mater. Rev. 34 (1989) 213.

[10] J.D. Kim, Y. Peng, J. Mater. Process. Technol. 104 (2000) 284.

[11] Y.T. Pie, J.Th.M. De Hosson, Acta Mater. 48 (2000) 2617.

[12] H.M. Krumbhaar, W. Kurz, E. Brener, in: G. Kostorz (Ed.), Phase Transformation in Materials, Wiley-VCH, Weinheim, Germany, 2001, p. 81.

[13] Ø. Grong, H.R. Shercliff, Prog. Mater. Sci. 47 (2002) 163.

[14] D. Turnbull, Acta Metall. 1 (1953) 684. 